\title{
Why Don't Employers Hire and Retain Workers with Disabilities?
}

\author{
H. Stephen Kaye $\cdot$ Lita H. Jans $\cdot$ Erica C. Jones
}

Published online: 13 March 2011

(C) The Author(s) 2011. This article is published with open access at Springerlink.com

\begin{abstract}
Introduction Despite persistently low employment rates among working-age adults with disabilities, prior research on employer practices and attitudes toward workers with disabilities paints a generally rosy picture of successfully accommodated workers in a welcoming environment. Findings from previous studies might have been biased because of either employer self-selection or social desirability, yielding non-representative or artificially positive conclusions. Methods In this study, a novel approach was used to survey human resource professionals and supervisors working for employers known or reputed to be resistant to complying with the ADA's employment provisions. Attendees of employer-requested ADA training sessions were asked to assess various possible reasons that employers in general might not hire, retain, or accommodate workers with disabilities and to rate strategies and policy changes that might make it more likely for employers to do so. Results As cited by respondents, the principal barriers to employing workers with disabilities are lack of awareness of disability and accommodation issues, concern over costs, and fear of legal liability. With regard to strategies employers might use to increase hiring and retention, respondents identified increased training and
\end{abstract}

\footnotetext{
H. S. Kaye ( $\square)$

Institute for Health and Aging, University of California

San Francisco, 3333 California Street Suite 340,

San Francisco, CA 94118, USA

e-mail: steve.kaye@ucsf.edu

L. H. Jans · E. C. Jones

DBTAC_Pacific ADA Center, Center On Disability,

Public Health Institute, Oakland, CA, USA

e-mail: research2@adapacific.org

E. C. Jones

e-mail: ericaj@adapacific.org
}

centralized disability and accommodation expertise and mechanisms. Public policy approaches preferred by respondents include no-cost external problem-solving, subsidized accommodations, tax breaks, and mediation in lieu of formal complaints or lawsuits. Conclusions Findings suggest straightforward approaches that employers might use to facilitate hiring and retention of workers with disabilities, as well as new public programs or policy changes that could increase labor force participation among working-age adults who have disabilities.

Keywords People with disabilities - Employment . Americans with Disabilities Act · Employer attitudes . Discrimination

\section{Introduction}

Decisions made by employers are critical to improving employment rates among working-age adults with disabilities. During the more than two decades since the Americans with Disabilities Act (ADA) was first proposed in the late 1980s, many researchers have surveyed employers about their attitudes toward hiring and retaining workers with disabilities and their experiences with accommodating such workers. The picture that has emerged is generally rather rosy, reflecting "a veneer of employer acceptance of workers with disabilities" [1]. Answers to general questions about workers with disabilities reflect particularly favorable attitudes. For example, two early studies of Fortune 500 corporations indicated favorable attitudes toward hiring people with intellectual and other significant disabilities, benefitting both the worker and the employer [2,3], and positive views of the job performance of workers with disabilities generally [4]. 
More recently, human resource and other high-level managers responding to one survey indicated generally favorable attitudes toward workers with disabilities [5]; respondents to that and a second survey expressed a moderate level of commitment to hiring workers with disabilities $[5,6]$.

A similar picture emerges when employers are asked about their experiences with accommodating workers with disabilities. In a 1998-1999 survey of private businesses and Federal agencies, a majority of human resource professionals from both types of organizations reported that they had accommodated workers with disabilities in each of the following ways: made their facilities more accessible, created flexible human resources policies, restructured jobs, modified the work environment, provided written job instructions, provided transportation accommodations, and modified equipment [7-9]. Additional accommodations available from a majority of employers, according to a 2010 survey, include flexible work schedules, telecommuting, and ergonomic redesign of workstations [10].

Employers report that accommodations provided to workers with disabilities typically cost little or nothing [11-15], but are generally effective [13] and "worth the investment" [6] in terms of retaining experienced workers and increasing productivity $[12,16]$, as well as improving organizational culture and climate [16]. In several general employer surveys, only a small minority cited concerns over the cost of accommodations as a reason for not hiring workers with disabilities $[6,7,10,11]$. Another potential financial concern is fear of litigation under the ADA or other non-discrimination laws, but employers rarely cite this as a barrier to hiring workers with disabilities. In one study, $4 \%$ of employers cited fear of litigation as a principal barrier [11], and, in another, this concern appeared fairly low on the list of most-often cited barrier to hiring workers with disabilities [17].

Notwithstanding a few other studies revealing somewhat negative attitudes, especially those asking employers about more stigmatized types of disability [18-20], most employer surveys appear to paint a picture of successfully accommodated workers in a more or less welcoming environment. If we were to accept such findings at face value, we would be left wondering why the employment situation for working-age adults with disabilities remains dismal a full two decades after the enactment of the ADA $[21,22]$. Workers and job seekers with disabilities, for their part, often cite employer attitudes and workplace discrimination as barriers to acquiring or keeping a job (see, e.g., [23-27]).

One explanation is that true employer attitudes and experiences are not being obtained from employer surveys, either because employers are not being completely honest or because only employers with positive attitudes and experiences are responding to the surveys. The former could be the result of social desirability bias [28], in which respondents essentially report what they think the interviewer wants to hear rather than expressing their true attitudes, which are socially unacceptable and may run counter to legal requirements [1, 29-31]. The latter explanation, that employers with negative attitudes are not part of the survey samples, might come about because such employers either decline to participate or, in surveys whose sample is selected from businesses expressing interest in hiring or accommodating people with disabilities (e.g., $[12,15]$ ), are not part of the sampling frame. Studies focusing on employers with a history of successful accommodation are unlikely to detect negative attitudes toward or unfavorable experiences with workers with disabilities.

The present study attempts to address both limitations. To reduce social desirability bias, we asked human resource professionals and managers why they thought other employers might not hire or retain people with disabilities. And to compensate for selection or non-response biases in other studies, we purposely sought employers known or reputed to be reluctant to complying with disability non-discrimination laws. Our results directly contradict many prior findings, and offer participants' perspectives on strategies that could help improve hiring and retention of workers with disabilities.

\section{Methods}

We began with the hypothesis that our study would yield distinctly different results from prior studies if we were able to collect data from a set of "ADA-recalcitrant" employers-businesses and government entities known or reputed to be reluctant to hire and accommodate workers with disabilities. We identified such employers from among those who were referred to or otherwise known by the DBTAC-Pacific ADA Center, one of ten regional Disability and Business Technical Assistance Centers (DBTAC) offering information and guidance on complying with the ADA and other disability laws to businesses, government entities, workers, and other consumers; the DBTAC maintains partnerships with local organizations throughout Federal Region IX, and these affiliates also identified candidate employers. Employers were considered ADA-recalcitrant if they had directly expressed resistance to complying with the ADA to DBTAC or affiliate staff; had established such a reputation among DBTAC staff, its local affiliates, or the disability community; or had been referred to the DBTAC because of an actual or threatened legal action or complaint against them or as part of a settlement of a lawsuit or complaint. 
Early attempts to question a few such employers directly about their attitudes and experiences were not successful, with participants becoming defensive and answering disingenuously, according to the interviewers' perceptions. Rethinking our strategy, we decided instead to use indirect or structured projective questioning, a technique suggested in the literature and found to be effective in reducing social desirability bias [32-34]. Instead of asking about the participants' own attitudes and experiences, we ask them to speculate as to the attitudes and behaviors of employers in general, not necessarily their own business or government entity. In a pilot test, this indirect method proved much more effective in engaging the participants to consider the reasons that employers might be reluctant to hire or retain workers with disabilities.

We developed a pair of paper-and-pencil questionnaires, the first on barriers to hiring and retaining workers with disabilities and the second on practical and policy strategies to improve hiring and retention. The first questionnaire contained two sets of statements asserting reasons that employers might be reluctant to hire (for the first set) or retain (for the second set) workers with disabilities, with each set beginning with the instruction, "Thinking about employers in general, and not necessarily the organization you work for, please give us your opinion about the following statements." The statements were prefaced by the question, "Why don't some employers hire people with disabilities?" or "...retain workers with disabilities?"

The statements that followed were of the form, "Some employers don't hire people with disabilities because..." followed by a reason and response choices of "Strongly agree," "Agree," "Disagree," and "Strongly disagree," along with "Don't know." The section on reasons for not hiring people with disabilities contained 14 statements, beginning with the most innocuous ("...they rarely see people with disabilities applying for jobs") and ending with the least innocuous ("...they discriminate against job applicants with disabilities"). Similarly, the section on reasons for not retaining workers with disabilities presented 12 statements, e.g., "...they believe that workers with disabilities can no longer do the basic functions of their jobs."

These statements were developed by the project team based on our review of the literature, our own prior research, and the experienced garnered through frequent interactions with employers on ADA and other disability non-discrimination issues; they were then refined and augmented after a pilot test. Following each list of statements, space was provided for respondents to add additional reasons and offer comments.

The second questionnaire, which asked respondents to rate the helpfulness of suggested practical or policy strategies in improving hiring and retention of people with disabilities, followed a similar format. Following another instruction to think "of employers in general, and not necessarily the organization you work for," statements were of the form, "Employers would be more likely to hire and retain workers with disabilities if they had..." or "if there were..." Eight statements focused on practical approaches, such as "a written company policy of nondiscrimination that includes disability," and another eight on policy strategies, such as "tax breaks for hiring and retaining workers with disabilities." Response categories were "Very helpful," "Helpful," "Not very helpful," and "Not helpful at all," plus "Don't know." Again, space was provided for additional strategies and comments.

Questionnaires were distributed to human resources professionals and managers working at ADA-recalcitrant organizations who attended ADA or other disability-related trainings provided by DBTAC-Pacific ADA Center and its affiliates. An introduction to the first questionnaire, required for human subjects approval, emphasized the voluntary nature of the survey and its confidentiality. Some 463 respondents, each attending one of 38 trainings, completed and returned questionnaires. Few attendees refused to participate entirely, although many declined to provide a response to one or more statements. To maximize anonymity, no information about the individual or the employer was collected on the questionnaires or provided to the researchers.

Item non-response (includes missing, ambiguous, or otherwise invalid) averaged about $3 \%$ for the first questionnaire and $2 \%$ for the second; "don't know" averaged about $8 \%$ for the first questionnaire and $5 \%$ for the second. Both missing and "don't know" responses have been excluded from the analysis; i.e., the percentages reported are of known responses.

\section{Results}

\section{Reasons for Not Hiring or Retaining Workers} with Disabilities

Table 1 lists the potential reasons offered to respondents as to why employers might not hire people with disabilities, ranked by the proportion in agreement with that reason (either "strongly agree" or "agree"). The top three reasons, each endorsed by more than four-fifths of respondents, refer to the cost of accommodations, lack of awareness as to how to deal with workers with disabilities and their accommodation needs, and fear of being stuck with a worker who cannot be disciplined or fired because of the possibility of a lawsuit. The next tier of reasons, agreed to by roughly $70 \%$ of respondents, are difficulty assessing an applicant's ability to perform job tasks, concerns over extra 
Table 1 Proposed reasons for employers not hiring people with disabilities, ranked by the proportion of respondents expressing agreement

\begin{tabular}{|c|c|c|c|c|}
\hline & \multirow[t]{2}{*}{ Reason } & \multicolumn{3}{|c|}{ Percent of respondents } \\
\hline & & $\begin{array}{l}\text { In } \\
\text { agreement* }\end{array}$ & $\begin{array}{l}\text { Strongly } \\
\text { agree }\end{array}$ & $\begin{array}{l}\text { Strongly } \\
\text { disagree }\end{array}$ \\
\hline 1 & $\begin{array}{l}\text { They are worried about the cost of providing reasonable accommodations } \\
\text { so that workers with disabilities can do their jobs }\end{array}$ & 81.4 & 30.1 & 2.9 \\
\hline 2 & They don't know how to handle the needs of a worker with a disability on the job & 80.9 & 25.4 & 4.1 \\
\hline 3 & $\begin{array}{l}\text { They are afraid they won't be able to discipline or fire a worker with a disability } \\
\text { for poor performance, because of potential lawsuits }\end{array}$ & 80.2 & 23.4 & 4.8 \\
\hline 4 & $\begin{array}{l}\text { They can't ask about a job applicant's disability, making it hard to assess whether } \\
\text { the person can do the job }\end{array}$ & 73.3 & 20.3 & 4.9 \\
\hline 5 & $\begin{array}{l}\text { They are concerned about the extra time that supervisors or co-workers will need } \\
\text { to spend to assist workers with disabilities }\end{array}$ & 70.9 & 14.8 & 3.8 \\
\hline 6 & $\begin{array}{l}\text { They are worried about other costs, such as increased health insurance } \\
\text { or worker's compensation premiums }\end{array}$ & 69.9 & 22.8 & 4.2 \\
\hline 7 & $\begin{array}{l}\text { They are afraid the workers with disabilities won't work up to the same standards as other } \\
\text { employees }\end{array}$ & 68.5 & 12.1 & 5.4 \\
\hline 8 & They rarely see people with disabilities applying for jobs & 66.3 & 12.5 & 8.0 \\
\hline 9 & $\begin{array}{l}\text { They believe that people with disabilities can't do the basic functions of the jobs they apply } \\
\text { for }\end{array}$ & 55.8 & 8.1 & 8.9 \\
\hline 10 & They discriminate against job applicants with disabilities & 53.3 & 12.8 & 12.6 \\
\hline 11 & They are concerned about attitudes of co-workers toward the person with a disability & 46.7 & 7.1 & 8.8 \\
\hline 12 & They find that job applicants with disabilities don't have the necessary skills and experience & 41.8 & 6.2 & 12.3 \\
\hline 13 & They think of workers with disabilities as "problem employees" & 40.9 & 5.9 & 12.3 \\
\hline 14 & They find that job applicants with disabilities don't present themselves well in interviews & 31.5 & 3.9 & 12.4 \\
\hline
\end{tabular}

Response categories were "strongly agree," "agree," "disagree," and "strongly disagree." Responses of "don't know" are treated as missing and not included in the percentages

* Response is "strongly agree" or "agree"

supervisory time, other cost worries, concern that the person with the disability won't perform as well as non-disabled workers, and lack of job applicants with disabilities.

More than half of respondents agreed that employers didn't hire workers with disabilities because they feel that workers with disabilities cannot perform essential job functions, and that employers discriminate against applicants with disabilities. The latter reason, however, was one of only four statements generating more than $10 \%$ strong disagreement.

Proposed reasons for not retaining workers with disabilities are shown in Table 2, again ranked by the proportion of respondents expressing agreement. Once again the three top-ranked reasons have about $80 \%$ or greater agreement, and the reasons are similar to those for hiring: lack of awareness as to how to handle the worker's needs; concern that workers acquiring disabilities will become liabilities, whether legal or financial; and concern over the cost of accommodations. Next follow concerns over job performance, other costs, difficulty assessing whether the worker can do the job, and belief that the person cannot do the job, all at $65 \%$ agreement or more. Only one additional reason, a belief that workers developing disabilities become less dependable (as opposed to less dedicated), was endorsed by more than half of the respondents.
Given space to write in additional reasons for not hiring or retaining workers with disabilities, or to comment on their responses, most participants either left the spaces blank or reinforced their agreement with the reasons presented to them, often supplying details or going beyond the statements we provided. After classifying the verbatim responses by topic (Table 3), we find that the most frequent remarks refer to employer concerns about job performance or qualifications. Many respondents felt that employers believed (or stated that they themselves believed) that a worker with a disability "doesn't pull his own weight," "can't do the job $100 \%$," or "might not have the same capacity" as other workers.

Some respondents referred specifically to essential job functions, but others said the problem was more subtle, related to what one respondent called "the 'other things' that come with the job." One wrote, "Employers want employees who are flexible and can do more than one task. They feel people with disabilities are limited." Another pointed out that "in this day and age workers need to multitask and assume different roles during emergencies," something he or she thought might be a problem for workers with disabilities. A separate, frequently mentioned issue was "greater absenteeism," "always calling in sick," 
Table 2 Proposed reasons for employers not retaining workers with disabilities, ranked by the proportion of respondents expressing agreement Reason

\begin{tabular}{|c|c|c|}
\hline \multicolumn{3}{|c|}{ Percent of respondents } \\
\hline $\begin{array}{l}\text { In } \\
\text { agreement* }\end{array}$ & $\begin{array}{l}\text { Strongly } \\
\text { agree }\end{array}$ & $\begin{array}{l}\text { Strongly } \\
\text { disagree }\end{array}$ \\
\hline 82.1 & 21.9 & 2.2 \\
\hline 80.3 & 16.4 & 3.3 \\
\hline 79.8 & 24.2 & 2.5 \\
\hline 72.1 & 11.9 & 2.8 \\
\hline 71.8 & 22.0 & 3.9 \\
\hline 68.4 & 16.8 & 3.8 \\
\hline 65.1 & 8.8 & 4.7 \\
\hline 60.1 & 4.9 & 5.7 \\
\hline 47.4 & 6.3 & 5.7 \\
\hline 42.2 & 4.5 & 7.4 \\
\hline 32.3 & 3.9 & 10.9 \\
\hline 31.6 & 2.4 & 17.3 \\
\hline
\end{tabular}

1 They don't know how to handle the needs of a worker with a disability on the job

2 They are afraid that workers who develop disabilities will become a liability to them

3 They are worried about the cost of providing reasonable accommodations so that workers with disabilities can do their jobs

4 They think that workers who are poor performers only get worse once they acquire a disability

5 They are worried about other costs, such as increased health insurance premiums

6 They can't ask about a worker's disability, making it hard to assess whether the person can still do the job

7 They believe that workers who develop disabilities can no longer do the basic functions of their jobs

8 They believe that workers who develop disabilities become less dependable

9 They are concerned about attitudes of co-workers toward the worker with a disability

10 They think of workers who develop disabilities as "problem employees"

11 They believe that workers who develop disabilities become less dedicated to their jobs

12 Workers who develop disabilities prefer not to return to work

Response categories were "strongly agree," "agree," “disagree," and "strongly disagree." Responses of "don't know" are treated as missing and not included in the percentages

* Response is "strongly agree" or "agree"

Table 3 Topics of verbatim additional responses and comments as to why some employers don't hire or retain workers with disabilities

\begin{tabular}{lrr}
\hline Subject & Respondents & $N$ \\
\cline { 2 - 3 } & Percentage & 13.1 \\
Concerns about job performance or qualifications & 9.7 & 57 \\
Employers don't know or understand disability or accommodation issues, need training & 6.7 & 4.4 \\
Concerns about cost, including accommodations, insurance, accessibility & 3.7 & 3.4 \\
Concerns about liability to lawsuits and complaints & 3.4 & 19 \\
Hassles such as paperwork, time spent learning about accommodations, etc.* & 2.5 \\
Employers' fear of the unknown* & 2.1 & 15 \\
Employer discrimination, ill will, relying on stereotypes of people with disabilities & 2.1 \\
Concerns over customer/client reaction or public image* & 1.4 \\
Employers uncomfortable around people with disabilities, don't know how to behave* & 1.4 \\
Concerns that the worker will not fit in or co-workers will react badly & 9 \\
Don't encounter or recruit applicants or workers with disabilities & 6 \\
Attitudes of workers with disabilities, including an attitude of entitlement* & 6 \\
\hline
\end{tabular}

* New topic distinct from reasons presented to respondents

"absence from work too often," or "time off from work for doctor's appointments"; several respondents appeared to hold these views themselves, indicating that they associate disability with poor health.

The next topic most often mentioned by respondents was "lack of knowledge or experience with people with disabilities," "misconceptions as to what a person with a disability is capable of," and lack of knowledge "about discrimination laws or reasonable accommodations." One respondent wrote,
"A lot of employers misunderstand or do not know the laws; they need to be educated." In addition to learning more about the ADA, "employers should have training on disabilities and how to accommodate or handle them." One respondent offered specifics: "Sometimes employers need help in 'rethinking' how the work can be completed. They need help in seeing how jobs can be done in a new way."

Next among the comments were concerns over costs, including those of making the worksite accessible, 
increased insurance premiums, and individual accommodations. Respondents also reinforced their agreement that fear of lawsuits and discrimination complaints was a central issue, along with the broader concern over liability in case of injury or accident.

Less frequently, respondents brought up issues that we had not included in our list of reasons for not hiring or retaining workers with disabilities. Several referred to the "hassle," "paperwork," or "trouble and effort" related to hiring or employing workers with disabilities, such as having to "spend time on issues they have never had to address before," "deal with government bureaucracy," or "be bothered researching accommodations." One respondent summed it up: "It is a big hassle to hire a person with a disability because there are a lot of government regulations to follow. Employers have so many laws they have to follow already."

Another topic introduced by the respondents was "fear of the unknown," repeatedly expressed in those or very similar words. One respondent felt that employers "may be afraid of people with disabilities, afraid of the unknown, and also afraid of certain disabilities more than others."

A related topic, also not included among our list of reasons, was discomfort in the presence of people with disabilities. Employers "see so few people with disabilities that they don't know how to act when they meet one." They "must always be careful of how different things need to be handled and must edit what is said or spoken to a person with disabilities," according to one respondent. Even if employers are themselves comfortable around workers with disabilities, they may fear that their customers or clients are not, according to several respondents. They might have vague concerns about "image," or may worry that "customers or members of the public that deal with the employee may have a reluctance or uneasiness in dealing with employees with disabilities," in the words of one respondent.

A final topic not included in our list was attitudes of workers and job applicants with disabilities, mentioned by only a few respondents. One referred to an "attitude of entitlement" that another summed up as, "I'm special, so treat me special." A third respondent explained, "Some people with disabilities expect employers and coworkers to give them special treatment and assistance beyond reasonable accommodations."

Many respondents wrote their comments in the first person and described their own experiences with and attitudes toward workers or applicants with disabilities, indicating that they were, at times, putting themselves in the position of the "other employers" they were asked to characterize. A few revealed disturbing attitudes reflecting personal prejudice and ignorance. One remarked-in the "any comments" area rather than the space for offering reasons other employers might not hire people with disabilities-that "people with disabilities don't think the same way as normal people." Another wrote, "I think that people with disabilities can't do the same things as people without disabilities."

In contrast, many other respondents, despite working for "ADA-recalcitrant" employers, expressed positive views of the potential and performance of workers with disabilities. These opinions were often grounded in personal experience with disability or success in hiring, retaining, or working with people with disabilities.

Strategies to Improve Hiring and Retention of Workers with Disabilities

For each of the practical strategies we proposed that organizations might use to improve hiring and retention of workers with disabilities, at least four-fifths of respondents regarded the strategy as either "very helpful" or "somewhat helpful." These strategies are shown in Table 4, ranked according to the proportion of respondents rating them as "very helpful." More or better training is ranked highest, followed by an organization-wide source of expertise on accommodation issues; both were rated "very helpful" by more than two-thirds of respondents. These were followed closely by written guidelines for dealing with disability and accommodation issues and an organization-wide system for handling accommodation requests.

Also regarded as "very helpful" by about $60 \%$ of respondents were external guidance on disability and accommodation issues and a diversity specialist within the organization to deal with disability issues. More than half of the respondents believed that a centralized fund to pay for job accommodations would be very helpful, as would a written non-discrimination policy that included disability status.

It is interesting to note that expertise in disability issues is the focus of most of the top-ranked strategies. These include increasing knowledge among managers and supervisors themselves (\#1), making available experts either within (\#2) or outside the organization (\#5) for managers and supervisors to consult with, or transferring the burden of solving accommodation problems from the managers and supervisors to an internal expert (\#4 and \#6).

Endorsement of public policy strategies to improving hiring and retention of workers with disabilities was not quite as enthusiastic, with "very helpful" ratings ranging from about one-third to nearly two-thirds of respondents. As shown in Table 5, accommodations subsidized or entirely paid for by a government agency ranks at the top of the list, followed by no-cost, outside help with solving disability- and accommodation-related issues. Just over half said that tax breaks for hiring and retaining workers with disabilities would be very helpful. 
Table 4 Practical strategies for improving hiring and retention of workers with disabilities, ranked by the proportion of respondents rating them "very helpful"

\begin{tabular}{|c|c|c|c|c|}
\hline & \multirow[t]{2}{*}{ Strategy } & \multicolumn{3}{|c|}{ Percent of respondents } \\
\hline & & $\begin{array}{l}\text { Very } \\
\text { helpful }\end{array}$ & $\begin{array}{l}\text { Somewhat } \\
\text { helpful }\end{array}$ & $\begin{array}{l}\text { Not } \\
\text { helpful* }\end{array}$ \\
\hline 1 & More or better training on disability issues for supervisors and managers & 74.4 & 22.2 & 3.4 \\
\hline 2 & A central organization-wide source for expertise on accommodation issues & 66.8 & 28.5 & 4.6 \\
\hline 3 & Written guidelines for dealing with disability issues, including accommodation requests & 65.2 & 29.1 & 5.6 \\
\hline 4 & An organization-wide system for handling requests for reasonable accommodations & 65.2 & 27.4 & 7.3 \\
\hline 5 & External resources to get guidance on disability and accommodation issues & 60.6 & 31.3 & 8.1 \\
\hline 6 & A diversity specialist who deals with disability issues & 58.4 & 31.0 & 10.6 \\
\hline 7 & A centralized fund within the organization to pay for job accommodations & 55.4 & 31.6 & 13.0 \\
\hline 8 & A written company policy of non-discrimination that includes disability & 50.7 & 34.6 & 14.7 \\
\hline
\end{tabular}

* Rated as "not very helpful" or "not helpful at all"

Table 5 Policy strategies for improving hiring and retention of workers with disabilities, ranked by the proportion of respondents rating them "very helpful"

\begin{tabular}{|c|c|c|c|c|}
\hline & \multirow[t]{2}{*}{ Strategy } & \multicolumn{3}{|c|}{ Percent of respondents } \\
\hline & & $\begin{array}{l}\text { Very } \\
\text { helpful }\end{array}$ & $\begin{array}{l}\text { Somewhat } \\
\text { helpful }\end{array}$ & $\begin{array}{l}\text { Not } \\
\text { helpful* }\end{array}$ \\
\hline 1 & $\begin{array}{l}\text { A government program to pay for or subsidize reasonable accommodations for workers } \\
\text { with disabilities }\end{array}$ & 65.1 & 27.5 & 7.4 \\
\hline 2 & $\begin{array}{l}\text { Someone to come in and help solve disability-and accommodation-related issues, } \\
\text { without cost to the employer }\end{array}$ & 62.6 & 30.4 & 7.0 \\
\hline 3 & Tax breaks for hiring or retaining workers with disabilities & 53.4 & 35.1 & 11.5 \\
\hline 4 & Salary subsidies for workers with disabilities & 46.4 & 35.0 & 18.7 \\
\hline 5 & A trial initial employment period for workers with disabilities & 45.4 & 30.0 & 24.6 \\
\hline 6 & $\begin{array}{l}\text { An external mediation service to help resolve disability and accommodation issues } \\
\text { without recourse to lawsuits }\end{array}$ & 44.6 & 39.8 & 15.6 \\
\hline 7 & An easy way to recruit applicants with disabilities to fill vacant jobs & 39.0 & 41.0 & 20.1 \\
\hline 8 & $\begin{array}{l}\text { An externally facilitated problem-solving group to address issues of accommodation } \\
\text { and retention }\end{array}$ & 32.7 & 45.0 & 22.3 \\
\hline
\end{tabular}

* Rated as "not very helpful" or "not helpful at all"

Some $45 \%$ indicated that an initial trial employment period for workers with disabilities would be "very helpful," but this idea is controversial, with about one-quarter regarding it as not helpful, the largest negative rating of any proposed solution. Also rated very helpful at about the $45 \%$ level were salary subsidies for workers with disabilities and external mediation to help resolve issues before they result in legal action.

In the spaces provided for additional practical and policy strategies and other comments, respondents who wrote anything at all mostly reinforced and offered details on the strategies they had already been presented with. As shown in Table 6, the most frequent responses pertained to educating employers "to change [their] mentality and perception against people with disabilities." Respondents suggested, for example, "training...that changes organizational perceptions of disability" including "an orientation for supervisors and managers about not discriminating against a person with a disability," "testimonies of successful employees with disabilities" and "presentations by employers who've hired successfully." Education is seen as "the silver bullet" to "de-mystify the myth that [workers with disabilities] can't do the job as well as someone without disabilities." Managers "should be exposed to persons with disabilities working so they can see first hand what they can do and how well the job gets done."

The next two topics mentioned in the comments relate to the bottom line, either with regard to incentives for hiring and retaining workers with disabilities or to subsidies for accommodations. Incentives could include tax breaks or subsidies for new workers, or programs similar to those 
Table 6 Subjects of verbatim additional responses and comments as to practical and policy strategies to improve hiring and retention of workers with disabilities
* New topic distinct from strategies presented to respondents

\begin{tabular}{llr}
\hline Subject & Respondents \\
\cline { 2 - 3 } & Percentage & $N$ \\
\hline Education and familiarization with people with disabilities and disability issues & 6.9 & 30 \\
Financial incentives for hiring and retention & 3.9 & 17 \\
Accommodation subsidies & 2.8 & 12 \\
Improve corporate culture* & 2.5 & 11 \\
Company policies and support from management and human resources & 1.6 & 7 \\
Training, mentoring, coaching of workers with disabilities; pre-employment & 1.6 & 6 \\
preparation* & & 6 \\
External help dealing with workers with disabilities and accommodations & 1.4 & 1.4 \\
Offer an opportunity to demonstrate abilities; trial employment period & 0.9 & 4 \\
Enforce existing laws* & &
\end{tabular}

offering incentives to minority- or women-owned suppliers or contractors: "Get them to hire them first and see their abilities. Then at least the worker has a foot in the door."

Improving corporate culture is a strategy mentioned by respondents but not explicitly included on our list. One respondent wrote, "Instilling diversity values in a corporation allows an arena for inclusion no matter what a person's orientation, race, or abilities." Another pointed out that "the commitment has to come from the top and filter down. Managers and supervisors who are change agents should be rewarded for their efforts." A third recommended a "partnership with ADA organizations to create a cohesive and accommodating work environment."

A second topic not included in the list of strategies involves training, not of employers but of workers and potential workers with disabilities. Respondents suggest that "agencies provide coaching or mentoring to the job applicant" or "offer a class to help develop résumés," and that there be "retraining of blue-collar workers to do whitecollar jobs."

\section{Discussion}

Human resources professionals and managers working for "ADA-recalcitrant" organizations were asked to use their experience to speculate as to the reasons that other employers fail to hire or retain workers with disabilities. The approach was aimed at reducing two perceived sources of bias in prior studies: social desirability bias, in which respondents don't report their true, negative beliefs to avoid social stigma, and selection or non-response bias, in which employers opposed to hiring or accommodating workers with disabilities failed to respond or were excluded from the sample. In the present study, respondents often revealed negative attitudes and mentioned discriminatory practices toward people with disabilities that are contrary to the ADA, and they indicated many reasons they felt employers might oppose having workers with disabilities on their payrolls.

In 468 questionnaires that were filled out and returned, four-fifths of respondents consistently endorsed three primary barriers to hiring and retention of workers with disabilities:

Ignorance

According to our respondents, employers often lack an awareness of how to deal with and accommodate workers with disabilities. As a result, they may feel that employing such a worker will entail an added burden to managers, supervisors, and human resource staff, in having to learn about the employer's responsibilities under the law, research appropriate accommodations, evaluate their costs and benefits, and deal with unforeseen issues that arise. Employers may not have been exposed to successfully employed and accommodated workers with disabilities, performing their jobs as well as anyone else, or to success stories from other employers. This lack of familiarity can manifest itself as reliance on stereotypes of people with disabilities as poor job performers, an erroneous belief that people with disabilities are often absent from work, and general social discomfort around workers and job applicants with disabilities. Despite two decades of programs to train employers on the ADA and familiarize them with disability issues, it is clear that there is a great deal more work to be done.

Costs

Concerns over the potential expense of accommodating a worker with a disability are also a major issue, according to the participants in our study, who contradicted findings from several other studies $[6,7,10,11]$. Despite the many studies [6, 11-15] indicating that the typical individual accommodation is inexpensive and more than pays for 
itself in increased productivity and the ability to retain an experienced worker, employers often see their obligation to provide "reasonable accommodations" as a substantial financial burden, one that harms the bottom line. They may also fear that they will need to make the entire workplace accessible, entailing a substantially larger cost. Beyond accommodations, cost concerns also extend to increased premiums for health insurance or workers compensation, as well as indirect costs such as extra supervisorial time or time needed to complete paperwork and deal with bureaucratic details.

\section{Legal Liability}

In the opinion of the survey respondents (but not of participants in previous studies [11, 17]), employers often worry that employing a worker with a disability puts them at risk of a lawsuit or a formal discrimination complaint (for example, to the Equal Employment Opportunity Commission or its state-level equivalent), or perhaps at legal and financial risk should a workplace injury or accident occur. They may partly fear making a mistake that gets them into trouble, or may see workers with disabilities as particularly litigious, people who might threaten legal action if they are terminated or disciplined for poor performance.

Another area of major concern was job performance. Most respondents believed that employers are concerned that workers with disabilities might not work up to the same standards as other workers, might present problems with illness and absenteeism, or might not be able to perform either essential job duties or other tasks needed to be effective employees in an increasingly demanding workplace. A major source of uneasiness appears to be a belief on the part of employers that the law prohibits them from asking applicants with disabilities whether and how they can perform job tasks. Again, their lack of familiarity with the ADA, and their fear of doing something that could get them sued, may contribute to this problem.

More than half the respondents agreed that discrimination is a reason that some employers don't hire workers with disabilities. If true, then reliance on stereotypes and old notions of disability is no doubt part of the motivation. Some respondents suggested additional motivations: fear of the unknown, which is occasionally mentioned in the literature [35, 36] as a reason employers are reluctant to employ workers with disabilities; and discomfort around people with disabilities, arising from lack of exposure (or "social distance"; see, e.g., [37]). The person doing the hiring might feel the discomfort himself or herself, or he or she might project that discomfort onto potential co-workers, clients, or customers: Will the person fit in? What will the customers think? Fears regarding reactions of customers are generally unfounded, according to one recent study revealing positive attitudes toward businesses that hire workers with disabilities [38].

Participants also rated proposed practical and policy strategies for improving hiring and retention of workers with disabilities. Solutions rated as most helpful addressed the principal barriers mentioned above:

\section{Awareness and Expertise}

The single solution most often endorsed by respondents is increased and improved training for supervisors and managers on disability issues. About three-quarters rated this strategy "very helpful," a finding may come as a surprise to the many organizations that have been training and providing ADA resources to employers for nearly two decades, as it did to the authors. Respondents' comments suggest that the need for information extends beyond employer responsibilities and recommended accommodations, to include exposure to successful employees with disabilities and to success stories from employers, strategies for rethinking job duties and engaging with workers with disabilities to understand accommodation needs and ways of achieving job tasks, and any type of presentation that would help dispel misconceptions and stereotypes and overcome prejudice.

Aside from instilling a general awareness in managers and supervisors, there was strong support among respondents for sources of expertise that managers and supervisors could turn to when needed. These include people within the organization tasked with the responsibility to assist with or handle accommodation and other issues, external resources to be consulted on such issues, and government-funded or other freely available experts from outside the organization who could come in and assist with solving specific accommodation problems. In general, transferring the decision-making burden from individual managers and supervisors to others within the organization-whether through formalized guidelines or specialists—was seen as highly beneficial.

\section{Subsidies and Financial Incentives}

A program of government subsidies for worker accommodations was rated "very helpful" by nearly two-thirds of respondents. Other highly rated solutions addressing cost concerns involved public policy strategies, namely tax breaks or salary subsidies for employing workers with disabilities, and practical strategies such as a central budget within the business or government entity for accommodations, so that the organizational units are not, in effect, financially penalized for hiring a worker with a disability. 


\section{Protection from Legal Risks}

Support was less than universal, but still substantial, for two policy strategies that could reduce employer concerns about being faced with lawsuits or discrimination complaints after hiring workers with disabilities. The less controversial approach was mediation in lieu of legal proceedings, in which an external service would be offered to resolve disability and accommodation issues, endorsed as "very helpful" by $45 \%$ of respondents. Endorsed by the same percentage, but also opposed by one-quarter of respondents, was a trial initial employment period, one that would allow the employer to dismiss a worker with a disability whose performance had not met expectations, without risking a lawsuit or complaint. Such a policy would, on the one hand, allow workers with disabilities to demonstrate their abilities, but might also open the door to treating such workers as casual employees subject to dismissal at the end of the trial period.

Respondents suggested solutions of their own, such as improving corporate culture to increase respect for disability as an aspect of a diverse workforce, better pre-application preparation for job applicants with disabilities, and job training so that workers acquiring disabilities can transition, for example, from blue-collar to white-collar occupations.

The findings from this study differ substantially from those of many previous studies, in that they paint what we believe is a more realistic picture of the concerns, fears, and general attitudes of employers toward workers with disabilities. They also offer recommendations for actions that, we feel, could substantially ease those concerns and fears and improve attitudes.

Organizations providing ADA and disability training to managers, supervisors, and human resources personnel need to expand their focus to emphasize not only legal requirements but also problem solving strategies, information resources, and concrete solutions to accommodation and disability issues. A greater emphasis needs to be placed on communicating to employers that people with disabilities can be effective, productive, and reliable employees; one approach would be to feature employed people with diverse disabilities as trainers or as participants in the training. Advice to employers should also include guidance on procedures they could implement to improve the accommodation process and ensure a more hospitable workplace for employees with disabilities.

Employers, for their part, could take a greater role in acquiring and centralizing the necessary information and expertise to better understand disability, appreciate workers' abilities, and solve accommodation problems. They could also create company-wide procedures, policies, and mechanisms to place less responsibility and burden on individual managers and supervisors and could work to improve corporate culture and better support managers and supervisors who are open to hiring and retaining workers with disabilities. The result might be a more diverse and accepting workplace for all employees, a more flexible approach to retaining skilled workers and hiring new employees, opportunities to increase productivity and take advantage of untapped talent, and a greater focus on job skills and performance rather than fear of potential future problems. Bringing in external experts to help with disability and accommodation issues, furthermore, could not only offer a broader range of solutions, but also demonstrate good faith and ensure fair treatment, and therefore potentially reduce legal liability.

Public policy regarding employment of workers with disabilities could be enhanced in several ways, the most obvious of which would be to use various means, including training, public awareness campaigns, and enhancing or better publicizing available resources, to encourage employers to take the above steps. Policies that ease the financial burden, whether imagined or real, of employing workers with disabilities should also be considered. Finally, to the extent that employer concern over lawsuits is a real barrier to employing workers with disabilities, it might be useful to evaluate policy changes that could reduce or address such fears. We believe that these practical and policy strategies, taken together, could help alleviate the intractable problem of low employment rates among working-age adults with disabilities.

Acknowledgment This research was funded by the National Institute on Disability and Rehabilitation Research, U.S. Department of Education, under grant \#H133A060098.

Open Access This article is distributed under the terms of the Creative Commons Attribution Noncommercial License which permits any noncommercial use, distribution, and reproduction in any medium, provided the original author(s) and source are credited.

\section{References}

1. Hernandez B, Keys C, Balcazar F. Employer attitudes toward workers with disabilities and their ADA employment rights: a literature review. J Rehabil. 2000;66(4):4-16.

2. Levy JM, Jessop DJ, Rimmerman A, Levy PH. Employment of persons with severe disabilities in large businesses in the United States. Int J Rehabil Res. 1991;14(4):323-32.

3. Levy JM, Jessop DJ, Rimmerman A, Levy PH. Attitudes of Fortune 500 corporate executives toward the employability of persons with severe disabilities: a national study. Ment Retard. 1992;30(2):67-75.

4. McFarlin DB, Song J, Sonntag M. Integrating the disabled into the work force: a survey of fortune 500 company attitudes and practices. Empl Responsib Rights J. 1991;4(2):107-23.

5. Chan F, Strauser D, Maher P, Lee EJ, Jones R, Johnson ET. Demand-side factors related to employment of people with disabilities: a survey of employers in the mid-west region of the United States. J Occup Rehabil. 2010;20(4):412-9. 
6. Unger DD, Wehman P, Yasuda S, Campbell L, Green H. Human resource professionals and the employment of people with disabilities: a business perspective. In: Unger DD, Kregel J, Wehman P, Brooke V, editors. Employers' views of workplace supports: Virginia Commonwealth University Charter Business Roundtable's national study of employers' experiences with workers with disabilities. Richmond: Virginia Commonwealth University; 2002.

7. Bruyere SM. Disability employment policies and practices in private and federal sector organizations. Ithaca: Cornell University, School of Industrial and Labor Relations Extension Division, Program on Employment and Disability; 2000.

8. Bruyere SM, Erickson WA, Van Looy S. Comparative study of workplace policy and practices contributing to disability nondiscrimination. Rehabil Psychol. 2004;49(1):28-38.

9. Bruyere SM, Erickson WA, VanLooy SA. The impact of business size on employer ADA response. Rehabil Couns Bull. 2006;49(4): 194-206.

10. Harris Interactive. Kessler foundation/NOD survey of employment of Americans with disabilities. N Y: Harris Interactive; 2010.

11. Dixon KA, Kruse D, Van Horn CE. Restricted access: a survey of employers about people with disabilities and lowering barriers to work. Work trends. New Brunswick, NJ: John J. Heldrich Center for Workforce Development, Rutgers University; 2003. Report no. 3.6.

12. Job Accommodation Network. Workplace accommodations: Low cost, high impact. 1 Sept 2010 [cited 5 Oct 2010]; http://AskJAN. org/media/LowCostHighImpact.doc.

13. Lee B, Newman K. Employer responses to disability: preliminary evidence and a research agenda. Empl Responsib Rights J. 1995;8(3):209-29.

14. Lee BA. Legal requirements and employer responses to accommodating employees with disabilities. Hum Resour Manag Rev. 1996;6(4):231-51.

15. Unger DD, Kregel J. Employers' knowledge and utilization of accommodations. In: Unger DD, Kregel J, Wehman P, Brooke V, editors. Employers' views of workplace supports: Virginia Commonwealth University Charter Business Roundtable's national study of employers' experiences with workers with disabilities. Richmond: Virginia Commonwealth University; 2002.

16. Hartnett HP, Stuart H, Thurman H, Loy B, Batiste LC. Employers' perceptions of the benefits of workplace accommodations: reasons to hire, retain and promote people with disabilities. J Vocat Rehabil. 2011;34(1):17-23.

17. Domzal C, Houtenville A, Sharma R. Survey of employer perspectives on the employment of people with disabilities: technical report. McLean: CESSI; 2008.

18. Diksa E, Rogers ES. Employer concerns about hiring persons with psychiatric disability: results of the employer attitude questionnaire. Rehabil Couns Bull. 1996;40(1):31-44.

19. Millington MJ, Szymanski EM, Hanley-Maxwell C. Effect of the label of mental retardation on employer concerns and selection. Rehabil Couns Bull. 1994;38(1):27.
20. Gilbride D, Stensrud R, Ehlers C, Evans E, Peterson C. Employers' attitudes toward hiring persons with disabilities and vocational rehabilitation services. J Rehabil. 2000;66(4):17-23.

21. Bureau of Labor Statistics. Persons with a disability: labor force characteristics: 2009. News release. Washington, D.C.: U. S. Department of Labor; 2010.

22. Kaye HS. The impact of the 2007-09 recession on workers with disabilities. Mon Labor Rev. 2010;133(10):19-30.

23. Brooks RA, Martin DJ, Ortiz DJ, Veniegas RC. Perceived barriers to employment among persons living with HIV/AIDS. AIDS Care. 2004;16(6):756-66.

24. Cook JA. Employment barriers for persons with psychiatric disabilities: update of a report for the president's commission. Psychiatr Serv. 2006;57(10):1391-405.

25. Honey A. The impact of mental illness on employment: consumers' perspectives. Work. 2003;20(3):267-76.

26. Wilson-Kovacs D, Ryan MK, Haslam SA, Rabinovich A. 'Just because you can get a wheelchair in the building doesn't necessarily mean that you can still participate': barriers to the career advancement of disabled professionals. Disabil Soc. 2008;23(7):705-17.

27. Shier M, Graham JR, Jones ME. Barriers to employment as experienced by disabled people: a qualitative analysis in Calgary and Regina, Canada. Disabil Soc. 2009;24(1):63-75.

28. Edwards AL. The relationship between the judged desirability of a trait and the probability that the trait will be endorsed. J Appl Psychol. 1953;37(2):90-3.

29. Unger DD. Employers' attitudes toward persons with disabilities in the workforce: myths or realities? Focus Aut Other Dev Disabil. 2002;17(1):2-10.

30. Ren LR, Paetzold RL, Colella A. A meta-analysis of experimental studies on the effects of disability on human resource judgments. Hum Resour Manag Rev. 2008;18(3):191-203.

31. Luecking RG. Emerging employer views of people with disabilities and the future of job development. J Vocat Rehabil. 2008;29(1):3-13.

32. Fisher RJ. Social desirability bias and the validity of indirect questioning. J Consum Res. 1993;20(2):303-15.

33. Fisher RJ, Tellis GJ. Removing social desirability bias with indirect questioning: is the cure worse than the disease? Adv Consum Res. 1998;25(1):563-7.

34. Supphellen M, Kvitastein OA, Johansen ST. Projective questioning and ethnic discrimination: a procedure for measuring employer bias. Pub Opin Quart. 1997;61(1):208-24.

35. Rinck C, Stickney S. Survey and focus groups of employers: Medicaid Infrastructure Grant. Kansas City: University of Missouri Kansas City; 2003.

36. Peck B, Kirkbride LT. Why businesses don't employ people with disabilities. J Vocat Rehabil. 2001;16(2):71-5.

37. Albrecht GL, Walker VG, Levy JA. Social distance from the stigmatized. A test of two theories. Soc Sci Med. 1982;16(14): 1319-27.

38. Siperstein GN, Romano N, Mohler A, Parker R. A national survey of consumer attitudes towards companies that hire people with disabilities. J Vocat Rehabil. 2006;24(1):3-9. 